T. O. PAUlisch, L. A. MAi, F. STRIETH-KALThOFF, M. J. JAMES, C. HENKEL, D. M. GULDi*, F. GLORIUS* (WESTFÄLISCHE WILHELMS-UNIVERSITÄT MÜNSTER, GERMANY)

Dynamic Kinetic Sensitization of $\beta$-Dicarbonyl Compounds - Access to Medium-Sized Rings via a De Mayo-Type Ring

Expansion

Angew. Chem. Int. Ed. 2021, DOI: 10.1002/anie.202112695.

\section{Iridium-Catalyzed Photosensitization of $\beta$-Dicarbonyls to Access Medium-Sized Rings}
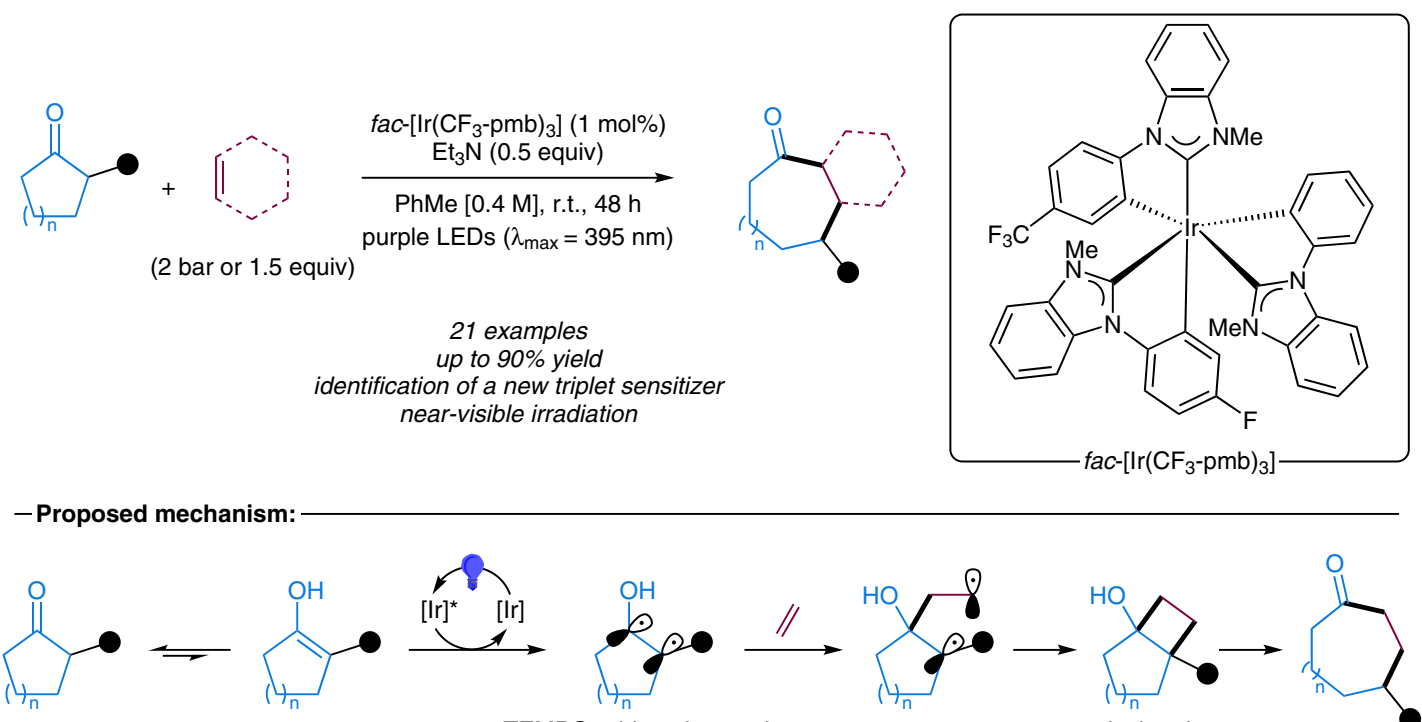

TEMPO adduct detected

\section{Category}

Metals in Synthesis

\section{Key words}

iridium catalysis

photosensitization

De Mayo reaction

medium-sized rings

\section{Synfact of the Month}

-Highlighted examples:<smiles>CCCCCCC1CC(C(C)=O)CCCC1=O</smiles>

$90 \%$ yield $\mathrm{rr}=55: 45$

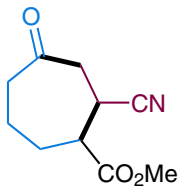

$52 \%$ yield $\mathrm{rr}=87: 13$

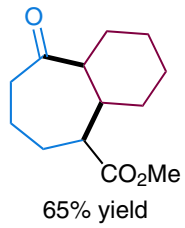

$65 \%$ yield

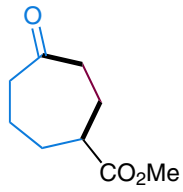

$82 \%$ yield

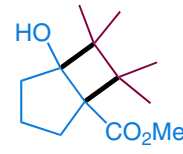

$36 \%$ yield

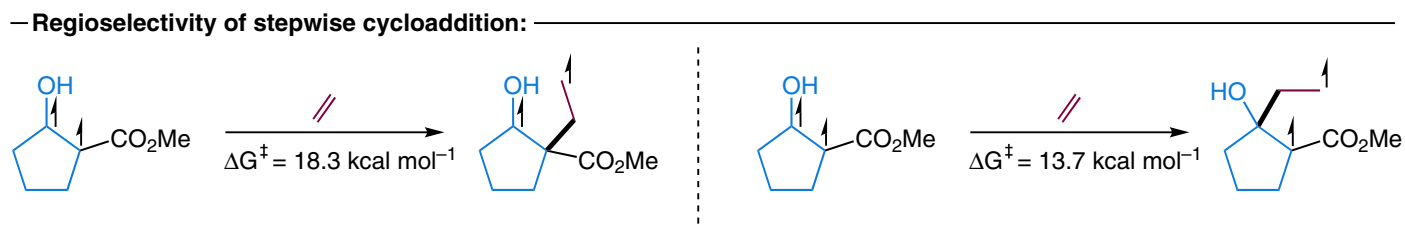

Significance: The authors report the synthesis of medium-sized rings via a De Mayo-type ring expansion. The use of fac-[ $\left[\mathrm{r}\left(\mathrm{CF}_{3}-\mathrm{pmb}\right)_{3}\right]$, a tris-cyclometalated complex bearing three $\mathrm{N}$-heterocyclic carbene ligands, as the photosensitizer is crucial for the reaction's success.
Comment: The reaction tolerates mono, 1,1-, and 1,2-disubstituted olefins as coupling partners. Heavily substituted olefins could not undergo the necessary retro-aldol reaction. Density functional theory suggests that the more nucleophilic $\alpha$-hydroxy radical adds preferentially to the alkene to begin the stepwise cycloaddition. 